\title{
Serum vitamin D levels in patients with oral lichen planus: A systematic review and meta-analysis
}

\author{
(1) Soundarya Sakthivel', (1) Sowndarya Gunasekaran², (1) Renita Lorina Castelino1, (1) Gogineni Subhas Babu', \\ (1) Vidya Ajila', (1) Sajad Ahmad Buch ${ }^{3}$
}

${ }^{1}$ Nitte (Deemed to be University) AB Shetty Memorial Institute of Dental Sciences (ABSMIDS), Department of Oral Medicine and Radiology, Mangalore, India

${ }^{2}$ Coorg Institute of Dental Sciences, Department of Pediatrics and Preventive Dentistry, Virajpet, India

3Yenepoya Dental College, Yenepoya (Deemed to be University), Department of Oral Medicine and Radiology, Mangalore, India

\section{Date submitted:}

09.12.2020

Date accepted:

31.01.2021

Online publication date:

15.12.2021

\section{Corresponding Author:}

Renita Lorina Castelino, MDS, Nitte

(Deemed to be University) AB Shetty

Memorial Institute of Dental Sciences

(ABSMIDS), Department of Oral

Medicine and Radiology, Mangalore, India

renita.castelino@yahoo.com

ORCID:

orcid.org/0000-0002-8696-549X

Keywords: Vitamin D, oral lichen

planus, calcitriol, 25(OH)D,

autoimmune disease

\begin{abstract}
Aims: Vitamin D is an indispensable vitamin which is actively engaged in immune upregulation. Several studies have been conducted to explore the association between vitamin $D$ and oral lichen planus (OLP), but the results are still inconclusive. This meta-analysis was performed to understand the association of serum vitamin D levels in OLP.
\end{abstract}

Methods: A search was conducted for observational studies that inspected the association between vitamin D and OLP from inception to June 2020 on scientific databases in accordance with PRISMA guidelines. The Newcastle-Ottawa Scale was used to assess the quality of the studies. Statistical analysis of the meta-analysis was performed with Review Manager version 5.4 .

Results: Five case-control studies met the selection criteria. The number of OLP cases ranged from 18 to 102 . Finally, 3 case-control studies were eligible for random-effects meta analyses of the mean difference in serum 25-hydroxyvitamin D concentrations between OLP cases and controls using inverse-variance method. The pooled mean difference in random-effects metaanalysis was 5.98 and this difefrence did not reach statistical significance.

Conclusions: The current meta-analysis showed numerically lower vitamin D level in patients with OLP, which was statistically non-significant.

\section{Introduction}

Erasmus Wilson was the first person to describe lichen planus in the year 1869. It is an autoimmune disease of the chronic type that affects the skin and mucous membranes. It can affect the skin, nails, hair, oral and genital mucosa (1). Oral lichen planus (OLP) has a prevalence of 0.5 to $2.2 \%$ in the general population and affects both women and men in the ratio of 3:2. At the time of diagnosis, the mean age is 55 years (2). World Health Organization has named OLP as a "Potentially Malignant Disorder" with an unspecified risk of malignant transformation
(3). Some studies have reported the malignant transformation rate of OLP as $0-12.5 \%$ (4). The etiology of OLP is multifactorial and many triggers for the disease have been identified so far: (a) cell mediated hypersensitivity, (b) autoimmune response to epithelial antigens, (c) stress, (d) viral infection (5). However, the role of the immune system in the etiopathogenesis of OLP is postulated by its histological features. The sub epithelial band of infiltration dominated by T-lymphocytes and macrophages and the liquefaction degeneration of the basal cells emphasize the role of the cell mediated arm of the immune system in the development of OLP. This is achieved by the cell mediated 
cytotoxity directed against antigens expressed by the basal cell layer (2).

Vitamin $\mathrm{D}$ is a secosteroid that aids in metabolism of calcium and phosphorus. The role of vitamin D, i.e. 25-hydroxyvitamin $D[25(\mathrm{OH}) \mathrm{D}]$, in the regulation of the immune system has been brought to light in recent literature. 25(OH)D inhibits the proliferation and differentiation of $\mathrm{B}$ cells and immunoglobulin secretion (6). In the $\mathrm{T}$ cells, it suppresses proliferation and maturation. There is a shift from Th1 to Th2 phenotype (7). This leads to a decrease in inflammatory cytokines such as interleukin (IL)-17 and IL-21 and increase in the production of anti-inflammatory cytokines such as IL-10. 25(OH)D inhibits the monocyte production from inflammatory cytokines such as IL-1, IL-6, IL-8, IL-12 and tumor necrosis factor-alpha (TNF-a) (8). It also inhibits dendritic cell differentiation and maturation $(9,10)$.

Multiple researches show that patients with autoimmune diseases like Behçet's diseases, rheumatoid arthritis, diabetes mellitus, systemic lupus erythematosus (SLE), inflammatory bowel disease and multiple sclerosis have decreased serum 25(OH)D levels compared to normal individuals. Faezi et al. (11) found that deficiency of $25(\mathrm{OH}) \mathrm{D}$ was more in patients with Behçet's disease compared to that of controls. Fakharan et al. (12) found that serum 25(OH)D levels inversely correlated with the activity of rheumatoid arthritis. Ibrahim et al. (13) conducted a study among multiple sclerosis patients and concluded that hypovitaminosis $\mathrm{D}$ was common among these patients. Schoindre et al. (14) found decreased levels of 25(OH)D in patients with SLE and a relationship between decreased $25(\mathrm{OH})$ $D$ levels and increased disease process (13). Hypovitaminosis D has not yet been recognized as a biomarker of OLP. The purpose of this systematic review was to analyze and quantitatively gather evidence associated with lower levels of serum $25(\mathrm{OH}) \mathrm{D}$ concentration and OLP patients.

\section{Methods}

\section{Search Strategy}

Search was conducted in databases like PubMed, Google Scholar, Cochrane library, Wiley online library and LILACS for relevant studies published till June 2020. The keywords used were 'oral lichen planus' or 'OLP' combined with 'Vitamin D' or 'Vit D' or '25(OH)D'. References of the relevant articles were searched to avoid missing any literature. Two researchers conducted the searches independently to identify quality articles. In case of disagreement, the third author decided whether the article was included.

\section{Selection Criteria}

Articles were included in this systematic review by going through the titles, abstracts and further reviewing the full text of the articles. The PRISMA flowchart of the selection process is depicted in Figure 1. The selected studies met the following inclusion criteria: 1) cohort, case-control or cross-sectional studies; 2) studies investigating the relationship between vitamin D and OLP; 3) studies of good quality; 4) studies published in English. The exclusion criteria for the studies included 1) case reports, reviews and editorials; 2) cells or animal studies; 3) serum level of vitamin $D$ estimated using indicators other than 25(OH)D; 4) Incomplete data. Of the 663 identified abstracts, 23 met the initial inclusion criteria. On the assessment of the full article, 17 were excluded because the outcome was not OLP and included cutaneous lichen planus and lichenoid reactions. The remaining 5 studies were included in this study (15-19).

\section{Data Collection}

The following data were extracted (Table 1): First author, publication year, study design, sample size, mean age, criteria for diagnosis of OLP, method of vitamin D estimation and serum vitamin D levels. Two authors extracted data independently, which were then reviewed by the third author. If the articles did not provide sufficient information, we tried our best to contact the authors. Since information only from existing published literature was included, no ethical committee approval or informed patient consent was acquired.

\section{Quality Evaluation}

Quality of the studies was evaluated using NewcastleOttawa scale (NOS) (20). It consisted of three parts: selection (0-4), comparability (0-2) and exposure/outcome (0-3). NOS scores of 1-3, 4-6 and 7-9 indicated the studies of low, medium and high quality. In this analysis, we used studies with NOS score $\geq 6$, which were of medium methodological quality (Table 2). Any disagreement among the researchers was resolved by discussion to reach a final consensus.

\section{Statistical Analysis}

Since the measurement of serum $25(\mathrm{OH}) \mathrm{D}$ is a continuous datum, the mean difference and $95 \%$ confidence interval were calculated. Heterogeneity was calculated with chi-square and $\mathrm{I}^{2}$ test (21). $\mathrm{I}^{2}>50 \%$ and $\mathrm{p}$ value $<0.01$ indicated substantial heterogeneity and random effects model was chosen in this circumstance. All the statistical analysis of this meta-analysis was carried out using Review Manager 5.4 (The Nordic Cochrane Centre, Copenhagen, Denmark). Results were presented as a forest plot (Figure 2).

\section{Results}

Included five studies were judged as medium quality in accordance with the NOS. Table 1 summarizes the studies included in this review (15-19). The studies were from the Northern hemisphere countries. Data collection was based on case-control studies. The number of cases ranged from 18 (17) to 102 (18) and the studies consisted of both men and women, with a women predominance. The mean age of cases ranged from 37 (15) to 51 (18) years. 


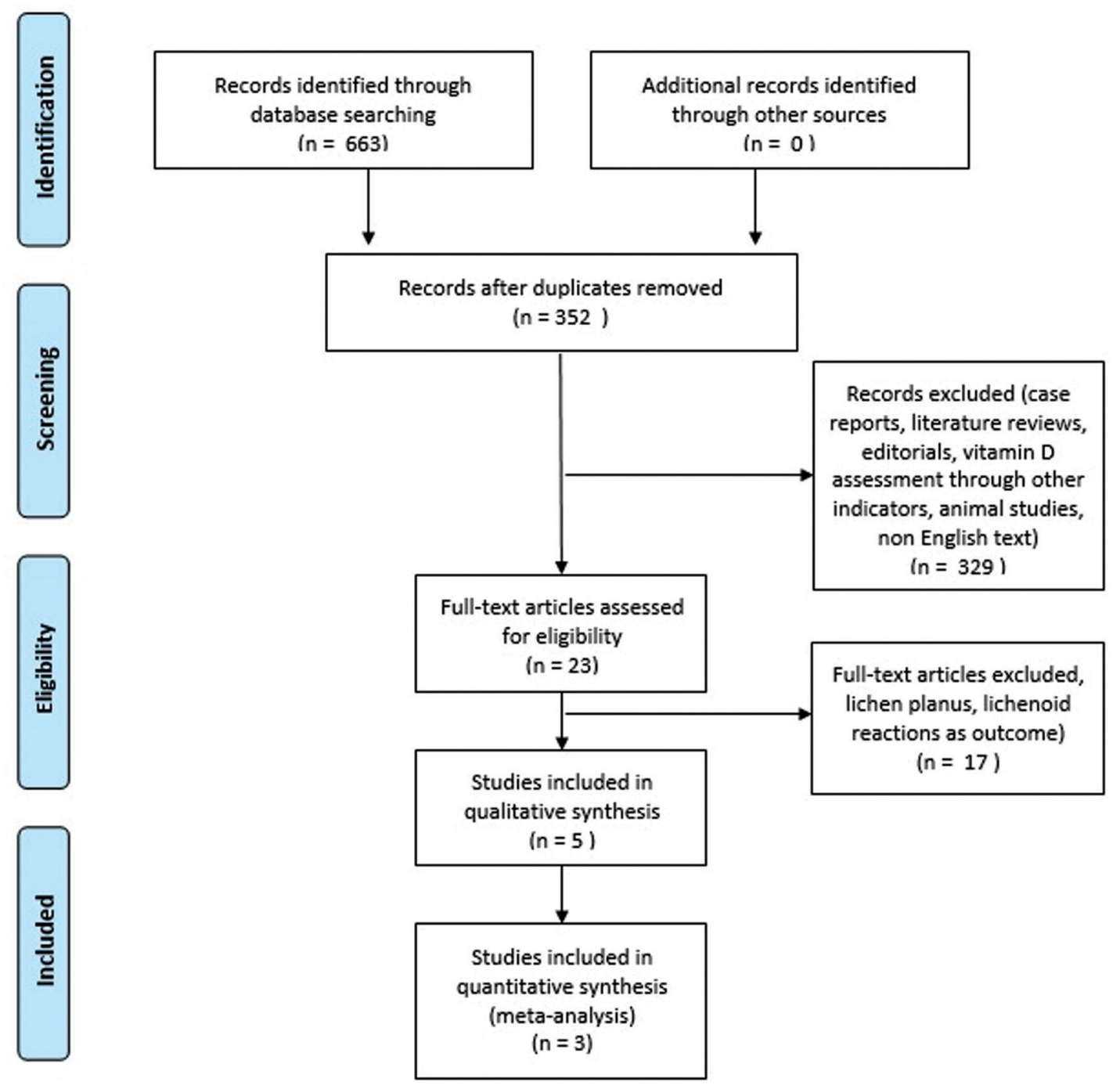

Figure 1. Prisma flow chart

\begin{tabular}{|c|c|c|c|c|c|c|c|c|c|c|}
\hline \multirow[b]{2}{*}{ Study or Subgroup } & \multicolumn{3}{|c|}{ control } & \multicolumn{3}{|c|}{ experimental } & \multicolumn{3}{|c|}{ Mean Difference } & \multirow{2}{*}{$\begin{array}{c}\text { Mean Difference } \\
\text { IV, Random, } 95 \% \mathrm{Cl}\end{array}$} \\
\hline & Mean & SD & Total & Mean & SD & Total & Weight & IV, Random, $95 \% \mathrm{Cl}$ & Year & \\
\hline Bahramian 2018 & 36.45 & 15.33 & 18 & 30.7 & 20.38 & 18 & $24.2 \%$ & $5.75[-6.03,17.53]$ & 2018 & \\
\hline Ahmed 2019 & 31.28 & 13.58 & 40 & 18.84 & 12.69 & 40 & $35.2 \%$ & $12.44[6.68,18.20]$ & 2019 & \\
\hline Golizadeh 2020 & 36.69 & 3.79 & 45 & 36.18 & 3.18 & 64 & $40.6 \%$ & $0.51[-0.84,1.86]$ & 2020 & \\
\hline Total $(95 \%$ Cl) & & & 103 & & & 122 & $100.0 \%$ & $5.98[-3.10,15.05]$ & & \\
\hline $\begin{array}{l}\text { Heterogeneity. Tau } \\
\text { Test for overall effect }\end{array}$ & $\begin{array}{l}52.32 \\
Z=1.2\end{array}$ & $\begin{array}{l}\mathrm{Ch}^{2}=16 \\
(P=0.2\end{array}$ & $0.20, d$ & $f=2(P$ & $=0.000$ & $8-$ & $\%$ & & & $\begin{array}{ccccc}1 & 1 & & 1 & 10 \\
-20 & -10 & 0 & 10 & 20 \\
\text { Favours [control] } & \text { Favours [exp] }\end{array}$ \\
\hline
\end{tabular}

Figure 2. Meta-analysis of the included studies. Forest plot showing serum vitamin D levels in patients with oral lichen planus and controls. Box area is proportional to the sample size of each study and the horizontal line corresponds to the $95 \%$ confidence interval. Black diamond corresponds to the summary value

All the studies measured the serum concentration of $25(\mathrm{OH})$ $\mathrm{D}$ as a continuous variable. Different techniques were used to estimate the $25(\mathrm{OH}) \mathrm{D}$ concentration and the most commonly used one was electro chemiluminescence technique (16-18).
The diagnosis of OLP in most studies was based on clinical views/clinicopathological criteria $(15,17,18)$. Two studies used the WHO criteria for diagnosis of OLP and oral lichenoid lesions $(16,19)$. In all studies, controls were healthy individuals from the hospital population. 
Table 1. Summary of included studies

\begin{tabular}{|c|c|c|c|c|c|c|}
\hline \multirow[t]{2}{*}{ Reference } & \multirow[t]{2}{*}{ Design } & \multirow[t]{2}{*}{ Location } & \multicolumn{2}{|c|}{ Participant categorization } & \multirow{2}{*}{$\begin{array}{l}\text { Vitamin D } \\
\text { measurement } \\
\text { method }\end{array}$} & \multirow[t]{2}{*}{ Result } \\
\hline & & & Case & Control & & \\
\hline $\begin{array}{l}\text { Gupta et al. (15) } \\
2017\end{array}$ & $\begin{array}{l}\text { Case-control } \\
\text { study }\end{array}$ & $\begin{array}{l}\text { Uttar } \\
\text { Pradesh, } \\
\text { India }\left(28.9^{\circ}\right. \\
\mathrm{N})\end{array}$ & $\begin{array}{l}102 \text { cases } \\
\text { - } 36 \text { males; } 66 \\
\text { females } \\
\text { - Based on clinical } \\
\text { views } \\
\text { - Mean age } 37.12 \text { y }\end{array}$ & $\begin{array}{l}102 \text { age } \\
\text { and gender } \\
\text { matched healthy } \\
\text { volunteers } \\
\text { from patient } \\
\text { population }\end{array}$ & $\begin{array}{l}\text { Enzyme linked } \\
\text { fluorescent assay } \\
\text { (Vitek } \\
\text { Immunodiagnostic } \\
\text { Assay System - } \\
\text { bioMérieux, Marcy- } \\
\text { l'Étoile, France) }\end{array}$ & $\begin{array}{l}\text { Mean } \\
\text { of } 25(\mathrm{OH}) \mathrm{D} \mathrm{in}: \\
\text { - Cases } 20.40 \mathrm{ng} / \\
\mathrm{mL} \\
\text { - Control } 32.67 \mathrm{ng} / \\
\mathrm{mL} \\
\mathrm{p}=0.000\end{array}$ \\
\hline $\begin{array}{l}\text { Tak et and } \\
\text { Chalkoo (16) } \\
2017\end{array}$ & $\begin{array}{l}\text { Case-control } \\
\text { study }\end{array}$ & $\begin{array}{l}\text { Jammu \& } \\
\text { Kashmir, } \\
\text { India }\left(34.0^{\circ}\right. \\
\mathrm{N})\end{array}$ & $\begin{array}{l}20 \text { cases } \\
\text { - Based on modified } \\
\text { WHO diagnostic } \\
\text { criteria of OLP and } \\
\text { OLL (2003) }\end{array}$ & $\begin{array}{l}20 \text { age and } \\
\text { gender matched } \\
\text { healthy controls } \\
\text { from patient } \\
\text { population }\end{array}$ & $\begin{array}{l}\text { Electro- } \\
\text { chemiluminescence } \\
\text { immune assay }\end{array}$ & $\begin{array}{l}\text { Cases <control } \\
p=0.0285\end{array}$ \\
\hline $\begin{array}{l}\text { Ahmed (18) } \\
2019\end{array}$ & $\begin{array}{l}\text { Case-control } \\
\text { study }\end{array}$ & $\begin{array}{l}\text { Erbil, Iraq } \\
\left(36.1^{\circ} \mathrm{N}\right)\end{array}$ & $\begin{array}{l}40 \text { cases } \\
\text { - Based on biopsy } \\
\text { and clinical or clinical } \\
\text { pathological criteria } \\
\text { - } 9 \text { males; } 31 \text { females } \\
\text { - Mean age } 51.7 \pm 10.8\end{array}$ & $\begin{array}{l}40 \text { age and } \\
\text { gender matched } \\
\text { healthy controls } \\
-11 \text { males; } 29 \\
\text { females } \\
\text { - Mean age } \\
49.2 \pm 11.2\end{array}$ & $\begin{array}{l}\text { Electro- } \\
\text { chemiluminescence } \\
\text { technique }\end{array}$ & $\begin{array}{l}\text { Mean } \pm \text { SD Of } \\
25 O H D \text { in: } \\
\text { - Cases } \\
18.84 \pm 12.69 \\
\text { - Controls } \\
31.28 \pm 13.58 \\
p<0.001\end{array}$ \\
\hline
\end{tabular}

\begin{tabular}{lllll}
\hline \multicolumn{2}{l}{ Table 2. Quality assessment of included studies using Newcastle-Ottawa scale } & & \\
\hline Reference & Selection & Comparability & Exposure/Outcome & Total \\
\hline Gupta et al. (15) & 3 & 1 & 2 & 6 \\
\hline Tak and Chalkoo (16) & 3 & 1 & 2 & 6 \\
\hline Bahramian et al. (17) & 3 & 1 & 2 & 6 \\
\hline Ahmed (18) & 3 & 1 & 2 & 6 \\
\hline Gholizadeh et al. (19) & 3 & 1 & 6 \\
\hline
\end{tabular}

Three of five studies found significant differences between the groups illustrated by lower levels of serum $25(\mathrm{OH}) \mathrm{D}$ in OLP cases compared to controls $(15,16,18)$. Most of the studies also showed that $25(\mathrm{OH}) \mathrm{D}$ insufficiency was more common in the controls compared to the OLP cases $(15,18)$.

All included studies showed that females were more affected compared with males which is in accordance with previously reported literature. In the study conducted by Ahmed (18), they inferred that reticular lichen planus was more widely prevalent followed by erosive and atrophic types. They also saw that the bilateral buccal mucosa was the most commonly affected site. Gholizadeh et al. (19) assessed the salivary flow rate in patients with OLP and found no significant association between salivary flow rate and levels of $25(\mathrm{OH}) \mathrm{D}$ in the serum and saliva. 
However, they observed a negative correlation between serum and saliva 25(OH)D levels and pain severity and score.

The meta-analysis was performed on 3 studies with a total of 122 cases and 103 controls (17-19). Two of the studies could not be included in the meta-analysis because the exact serum concentration of $25(\mathrm{OH}) \mathrm{D}$ with standard deviation was not provided $(15,16)$. The obtained mean difference ranged from 0.51 to 5.75 , on a scale where 0 corresponds to no difference between OLP cases and controls, and positive mean difference indicated that the OLP cases had lower vitamin D levels than controls. In two of the three studies, the $\mathrm{Cl}$ lower limits were negative $(17,21)$. The summary random mean difference of 5.98 indicated that serum vitamin D concentrations were overall 5.98 SD lower in OLP cases compared to controls. However, the summary value of mean difference crosses the zero line and reaches the negative scale, which indicates that this difference in the concentrations of serum $25(\mathrm{OH}) \mathrm{D}$ in OLP patients and controls holds no statistical significance.

\section{Discussion}

This study aimed to improve awareness regarding the potential role of vitamin D in the disease process of OLP and open numerous venues of future research in the same way. Very few studies which investigated vitamin D in OLP were identified in the existing literature. All included studies were cross sectional in nature.

Deficiency of vitamin $D$ has become widespread in the general population. This may be due to various reasons like decreased intake in diet or decreased absorption, inadequate endogenous synthesis, insufficient sun exposure due to decreased outdoor activity, conservative clothing, increased use of sunscreens and intake of medications that increase metabolism of vitamin $D$ (22). Hence researchers have been keen on investigating the link between decrease in vitamin $D$ levels and various disease processes.

Past two decades of researches have established that $25(\mathrm{OH}) \mathrm{D}$ regulates the immune response mechanism, other than calcium homeostasis and bone metabolism. This was brought to light by the discovery that $25(\mathrm{OH}) \mathrm{D}$ could affect the production of ILs. These ILs belong to a group of cytokines, which facilitate the interaction between immune and inflammatory cells by influencing cell growth, differentiation and activation. ILs are synthesized in various cells like leukocytes, keratinocytes, trophoblasts, adipocytes, endothelial cells and other cell variants involved in specific organ related diseases. 25(OH)D has been shown to strongly influence the expression of cytokines like ILs, TNF- $\alpha$, interferon-gamma (IFN- $\mathrm{Y}$ ), growth factors toll-like receptors, C-reactive protein and enzymes like cyclo-oxygenase, 5-lipoxygenase which generate inflammatory mediators (23). These components cause apoptosis of the keratinocytes which leads to OLP. $25(\mathrm{OH}) \mathrm{D}$ induces the expression of vitamin $\mathrm{D}$ receptors (VDR) in the epithelial cells (24).
Many studies have studied the influence of VDR on immune cells and cascades that promote inflammation. Du et al. $(24,25)$ and Zhao et al. (26) showed that vitamin D/VDR signaling reduces apoptosis of epithelial cells by suppressing LPS induced p53 upregulated modulator of apoptosis (PUMA) via nuclear factor-kappa B (NF-kB) pathway blockade. Zhao et al. (27), in 2019, mentioned that vitamin D/VDR signaling also suppressed LPS induced hypoxia inducible factor-1 $\alpha$ via NF-kB pathway blockade. This reduces the production of IFN-y and IL$1 \beta$. Ge et al. (28), in 2019, found that vitamin D/VDR signaling inhibited miR-802 expression, which causes cell apoptosis, via NF-kB pathway blockade.

In 2020, it was found that microRNA26a/b (29) and microRNA $27 \mathrm{a} / \mathrm{b}(30)$ were significantly decreased in the saliva, serum and tissue samples of patients with OLP. They identified that these microRNA had specific sites for binding VDR in their promoter region and that vitamin D/VDR signaling induced the expression of these microRNA in OLP patients. These microRNAs thereby play a protective role by inhibiting apoptosis and reducing proinflammatory cytokines. These findings show that $25(\mathrm{OH})$ D plays a vital role in inhibiting keratinocyte apoptosis which takes place in OLP and deficiency states of vitamin D can lead to increased possibility of OLP. This is substantiated by vitamin D supplementation improvement in OLP cases. Razi et al. (31) observed that premenopausal women with OLP, who were given supplements of vitamin D along with routine treatment, showed clinical improvement within the first four weeks compared to women who received routine treatment and showed improvement much later. Gupta et al. (32) found significant symptomatic improvement in patients who were given vitamin D supplementation along with topical steroid application and psychiatric consultation compared to the group of patients who did not receive vitamin $D$ supplementation.

This systematic review showed a definite association between 25(OH)D levels and the occurence and severity of OLP. The meta-analysis also showed no statistical significance but this could be attributed to the various previously discussed factors.

Females were more affected compared with males in the current study, which is in accordance with previously reported literature. In the study conducted by Ahmed (18), they inferred that reticular lichen planus was more widely prevalent followed by erosive and atrophic types. They also observed that the bilateral buccal mucosa was the most commonly affected site. Gholizadeh et al. (19) assessed the salivary flow rate in patients with OLP and found no significant association between salivary flow rate and levels of $25(\mathrm{OH}) \mathrm{D}$ in the serum and saliva. However, they observed a negative correlation between serum and saliva $25(\mathrm{OH}) \mathrm{D}$ levels and pain severity and score. 


\section{Conclusion}

Although numerous treatment modalities are available for OLP, a definitive treatment option is yet to be identified. The association of vitamin $\mathrm{D}$ with various autoimmune diseases and the improvement of such diseases with its supplementation has been documented in literature. The analysis we conducted has shown lower vitamin D level in patients with OLP, although statistically non-significant. Hence well-designed prospective studies with large sample sizes need to be performed. Longitudinal studies comparing variations in the serum vitamin $D$ levels and severity of the disease and trials of supplementation with vitamin $D$ in OLP patients with deficiency to observe improvement need to be conducted. These studies will aid in establishing the role of vitamin $D$ in the disease process of OLP. These results reinforce the conceptualization of vitamin $D$ as a potential biomarker and a definitive treatment modality for the enigma, which is OLP.

\section{Ethics}

Ethics Committee Approval: Since information only from existing published literature was included no ethical committee approval was acquired.

Informed Consent: Since information only from existing published literature was included no informed patient consent was acquired.

Peer-review: Externally peer-reviewed.

\section{Authorship Contributions}

Concept: R.L.C., Design: R.L.C., Data Collection or Processing: S.S., S.G., R.L.C., Analysis or Interpretation: S.G., S.A.B., Literature Search: S.S., G.S.B., V.A., Writing: S.S., S.A.B.

Conflict of Interest: No conflict of interest was declared by the authors.

Financial Disclosure: The authors declared that this study received no financial support.

\section{References}

1. Al-Hashimi I, Schifter M, Lockhart PB, et al. Oral lichen planus and oral lichenoid lesions: diagnostic and therapeutic considerations. Oral Surg Oral Med Oral Pathol Oral Radiol Endod. 2007;103(Suppl):S25.e1-12.

2. Glick M. Red and White lesions of the oral mucosa. In: Burket's Oral Medicine, eBook. 12th ed. USA: People's Medical Publishing House. 2015:104.

3. Warnakulasuriya S, Johnson NW, van der Waal I. Nomenclature and classification of potentially malignant disorders of the oral mucosa. J Oral Pathol Med. 2007;36:575-580.

4. Gonzalez-Moles MA, Scully C, Gil-Montoya JA. Oral lichen planus: controversies surrounding malignant transformation. Oral Dis. 2008;14:229-243.
5. Kurago ZB. Etiology and pathogenesis of oral lichen planus: an overview. Oral Surg Oral Med Oral Pathol Oral Radiol. 2016;122:72-80.

6. Chen S, Sims GP, Chen XX, Gu YY, Chen S, Lipsky PE. Modulatory effects of 1,25-dihydroxyvitamin D3 on human B cell differentiation. J Immunol. 2007;179:1634-1647.

7. Boonstra A, Barrat FJ, Crain C, Heath VL, Savelkoul HF, O'Garra A. 1alpha,25-Dihydroxyvitamin d3 has a direct effect on naive CD4(+) T cells to enhance the development of Th2 cells. J Immunol. 2001;167:4974-4980.

8. Almerighi C, Sinistro A, Cavazza A, Ciaprini C, Rocchi G, Bergamini A. 1Alpha,25-dihydroxyvitamin D3 inhibits CD40L-induced pro-inflammatory and immunomodulatory activity in human monocytes. Cytokine. 2009;45:190-197.

9. Piemonti L, Monti P, Sironi M, et al. Vitamin D3 affects differentiation, maturation, and function of human monocytederived dendritic cells. J Immunol. 2000;164:4443-4451.

10. Széles L, Keresztes G, Töröcsik D, et al. 1,25-dihydroxyvitamin D3 is an autonomous regulator of the transcriptional changes leading to a tolerogenic dendritic cell phenotype. J Immunol. 2009;182:2074-2083.

11. Faezi ST, Ansari N, Paragomi P, Akhlaghi M, Ghanavat M, Davatchi F. Vitamin D deficiency in patients with Behcet's disease. J Diabetes Metab Disord. 2014;13:18.

12. Fakharan $M$, Haghighi $A$, Arabi M, Loghman M. Investigating the levels of serum vitamin $d$ in patients with rheumatoid arthritis referred to rasoul-akram hospital during 20112012. Iran J Med Sci. 2014;39:476-479.

13. Ibrahim MH, Alloush TK, Rahim MK. Vitamin D Level in Multiple Sclerosis Patients. Could Vitamin D Level Be Routine Investigation for Multiple Sclerosis Patients? Sci Res Neuroscience \& Medicine. 2014;5:201-204.

14. Schoindre $\mathrm{Y}$, Jallouli M, Tanguy ML, et al. Lower vitamin D levels are associated with higher systemic lupus erythematosus activity, but not predictive of disease flareup. Lupus Sci Med. 2014;1:e000027.

15. Gupta A, Mohan RP, Kamarthi N, Malik S, Goel S, Gupta S. Serum Vitamin D Level in Oral Lichen Planus Patients of North India-A Case-control Study. J Dermatol Res Ther. 2017;1:19-35.

16. Tak MM, Chalkoo AH. Vitamin D deficiency - A possible contributing factor in the aetiopathogenesis of Oral lichen planus. J Evol Med Dent Sci. 2017;6:4769-4773.

17. Bahramian A, Bahramian M, Mehdipour M, et al. Comparing Vitamin D Serum Levels in Patients with Oral Lichen Planus and Healthy Subjects. J Dent (Shiraz). 2018;19:212-216.

18. Ahmed SA. The Role of Serum Vitamin D Deficency in oral Lichen Planus Case Control Study. DJM. 2019;17:189198.

19. Gholizadeh N, Pirzadeh F, Mirzaii-Dizgah I, Sheykhbahaei $\mathrm{N}$. Relationship between salivary vitamin $\mathrm{D}$ deficiency and oral lichen planus. Photodermatol Photoimmunol Photomed. 2020;36:384-386. 
20. Stang A. Critical evaluation of the Newcastle-Ottawa scale for the assessment of the quality of nonrandomized studies in meta-analyses. Eur J Epidemiol. 2010;25:603-605.

21. Higgins JP, Thompson SG. Quantifying heterogeneity in a meta-analysis. Stat Med. 2002;21:1539-1558.

22. Sizar O, Khare S, Goyal A, Givler A. Vitamin D Deficiency. In StatPearls. Treasure Island: StatPearls Publishing. 2020.

23. Skrobot A, Demkow U, Wachowska M. Immunomodulatory Role of Vitamin D: A Review. Adv Exp Med Biol. 2018;1108:13-23

24. Grimm M, Cetindis $M$, Biegner $T$, et al. Serum vitamin $D$ levels of patients with oral squamous cell carcinoma (OSCC) and expression of vitamin D receptor in oral precancerous lesions and OSCC. Med Oral Patol Oral Cir Bucal. 2015;20:e188-195.

25. Du J, Li R, Yu F, et al. Experimental study on 1,25(OH)2 D3 amelioration of oral lichen planus through regulating NF-KB signaling pathway. Oral Dis. 2017;23:770-778.

26. Zhao B, Li R, Yang F, et al. LPS-induced Vitamin D Receptor Decrease in Oral Keratinocytes Is Associated With Oral Lichen Planus. Sci Rep. 2018;8:763.
27. Zhao B, Xu N, LiR, etal. Vitamin D/VDR signaling suppresses microRNA-802-induced apoptosis of keratinocytes in oral lichen planus. FASEB J. 2019;33:1042-1050.

28. Ge X, Wang L, Li M, et al. Vitamin D/VDR signaling inhibits LPS-induced IFNy and IL-1 $\beta$ in Oral epithelia by regulating hypoxia-inducible factor-1 $\alpha$ signaling pathway. Cell Commun Signal. 2019;17:18.

29. Du J, Gao R, Wang Y, et al. MicroRNA-26a/b have protective roles in oral lichen planus. Cell Death Dis. 2020;11:15.

30. Ge X, Yuan L, Wei J, et al. Vitamin D/VDR signaling induces miR-27a/b expression in oral lichen planus. Sci Rep. 2020;10:301.

31. Razi A, Mohiuddin S, Abdulkarim A, Iqbal A. Vitamin D as an adjuant therapy to cure oral lichen planus in perimenopausal women. PODJ. 2018;38:399-403.

32. Gupta J, Aggarwal A, Asadullah M, Khan MH, Agrawal N, Khwaja KJ. Vitamin D in the treatment of oral lichen planus: A pilot clinical study. JIAOMR. 2019;31:222-227. 